\title{
Validation of Non-Formal Learning in Russia: New Challenges
}

\author{
Elena Murugova ${ }^{1, *}$, Tatyana Mikheeva ${ }^{2}$ \\ ${ }^{1}$ Don State Technical University, 1, Gagarin sg, 344000, Rostov-on-Don, Russia
}

\begin{abstract}
This paper is intended to cover some major issues in the sphere of non-formal education in Russia and its validation. The ratio of "formal" and "non-formal learning" is the main aspect of solving the problems of the advanced development of public education systems. It is illuminated that the official education systems are slowly adjusting to socio-economic development, their own conservatism as well as the inertia of societies contributes to this fact. Modern society has already had the opportunity to make sure that non-formal education is stronger, as the formal education system is not able to reverse the result of non-formal human socialization. The aim of this paper is to present the relevance of this topic for Russia, as the creation of efficient model of non-formal validation will meet the needs of people of different ages, especially adults, to implement the so-called lifelong learning in life. The paper reviews international leading literature in this subject focusing on its practical application and including the results of Russian participation in international VALERU project.
\end{abstract}

\section{Introduction}

Numerous attempts have been made to show the discrepancy between formal, informal and non-formal education [1]. This tripartite categorization of education was based primarily on the works of Coombs and Ahmed [2]. It is difficult to exaggerate how much have been done by European scientists in the field of "non-formal education" that mainly concerned "the contents of activities structured and organized in an institutionalized framework, with an optional character, complementary to school made within organizations for youth, leagues and pupils/students' associations, clubs, artistic and sporting associations. All these types of actions have a flexible character and are varied, offering the students the chance to choose according to their interests and abilities" [3].

Today in Europe, the term "non-formal education" refers to various educational practices that do not require a diploma [4]. In the late XIX and mid-twentieth century the innovative ideas advanced by the philosopher and psychologist D. Dewey [5] had immediate practical implications that made this type of education a successful business. One of the objectives of the development of non-formal education in Europe is its accessibility. The implementation of non-formal education in Russia is presented as an innovative approach in education. However, at present, in Russia there is an obvious low level of citizen participation in these educational sectors due to the absence of recognition procedures based on the learning

\footnotetext{
*Corresponding author: murugovaelena@yandex.ru
} 
outcomes. Moreover, the Russian state educational policy does not cover the "non-formal" and "informal education". The transition to such a system will result in the reform of the existing education system, which is not always freely perceived by the educational community.

\section{Purpose of the Present Study}

Research in this problem area contributes to the pivotal necessity to monitor the system of non-formal education in various educational segments for efficient model identification; analytical comparison of the national system with the foreign one and to the development of administrative procedures as well as the criteria of learning outcomes assessment for a competitive and successful future of Russia [6]. In the present study, we not only examined patterns of non formal validation in European countries but also identified the necessity of Russian validation model design. This allowed us to bring together competence-based education, student-centered and transparent learning outcomes and demonstrate the relevance of VNIL implementation.

\section{Validation in Russia: major difficulties and peculiarities}

The major attractions of non-formal validation methodology in the European context are connected with the transparency of its basic principles, the logical description of the validation procedures and its ability to apply the reconciled educational models of different countries through finding common reference points [7-14].

We should admit the existing social need, present and future, for non-formal and informal validation. The number of people in Russia who decide to pursue their second degree in another country is increasing. A parallel need for employment came from the perspective of the students, their families. In the European context the term validation has become the umbrella term for different understandings such as "the accreditation of prior learning, accreditation of learning outcomes, recognition of learning outcomes, prior learning, certification of prior learning and certification of learning outcomes" [15]. Validation in Russia has its own peculiarities reflected in the definition of this process. In the Russian context, it is conducted that academic validation is the education recognition abroad and professional validation is treated as the allowance to work in the Russian Federation. For this procedure, the language of learning outcomes is used [16]. Moreover, validation depends on the recognition of the achieved number of outcomes. For Russia, it is really a new model. The key focus is on the quality of the validation process with regard to orientation and assessment and its efficiency and effectiveness, the design of new practically oriented profiles. The best way to put this in practice is to conduct a cession of trainings for all the stakeholders. It is not an easy matter to validate a learning experience, to transfer non-formal learning into formally received qualifications. What is clear is that, firstly, we need time to create a new system for different forms of education validation and, secondly, we should force HELs to apply the new format of validation starting with the change in mentality to lead to productive not mechanical application of the new language. The following challenges in this field within the Russian context were spotted: current legislation in Russia, the Qualifications Framework, educational standards, the weakness of professional standards system, the issue of terminology, mismatch between curriculum and educational program, issue of credits vs. grading system, no standardized procedure in place, lack of clarity for responsibility within the university, vagueness of experts competence [17, 18, 19, 20, 21]. Don State Technical University (DSTU) is one of the leading technical universities in the South of Russia. It successfully participates in the integration of European Higher Education 
according to Bologna process. It provides education in different fields of science (engineering is major, computer sciences, physical and mathematical sciences, economics, socialhumanitarian sciences) with the following degrees: BSc, Engineer (Specialist), MSc, PhD, Doctor of Science. DSTU has a key role in developing appropriate strategies aimed to prepare their students for a productive career and for citizenship. The university is developing its internationalization strategies and activities for the integration into European educational area. One of the important points to pay attention to is that the Don State Technical University is one of the co-founders of Bologna Club in Russia. Being the active participant of $\mathrm{BC}$ the University disseminates the learning outcomes and take active part in modernization of $\mathrm{HE}$ in RU and CIS.

The validation procedures to some extent are relevant for the international Tuning methodology, its subject-arear-specific recommendations within the framework of Tuning Educational Programs in Russian HELs TEMPUS project. The Tuning model is focused on "measurable learning outcomes, designed competences, teaching and learning approaches and methods of assessment" [22].

\section{Validation procedure}

The validation methodology in its turn entails the model of validation, definitions of validation, national frame conditions and regulations, the procedures, a peculiar system of quality assurance, evidence of HEL's cooperation with employers in validation. For better application, it is required to be equipped with a practical knowledge, to make comparative analysis of NIL validation - advantages and disadvantages and to elaborate intercultural system for validation.

Validation can normally be oulined in four distinct options: "identification through dialogue of particular experiences of an individual; documentation to make visible the individual's experiences" [23] formal assessment of these experiences; and recognition leading to certification. It is vital to differentiate non-formal learning and informal one.

For validation procedure, the language of learning outcomes is used. This approach allows a broad variety of routes focuses on the orientation of the individual, covering some aspects of the process of assessment, from requirements to the identification of learning, the search for evidence until organizing it for assessment. In the present context, it takes time to plan, develop and approve degrees. The most important is the quality of the validation process with regard to orientation and assessment and its efficiency and effectiveness. Different approaches to validation and technologies (reflective essay, interview, portfolio, etc.) can be utilized. The validation procedure starts with reflective review writing on your skills, work experience and ends with the recognition of education for past learning.

Following the experience of other European universities and international project "Validation of Non-formal and Informal Learning in the Russian Federation" (VALERU) perspectives, it is important to establish a special body at host university to be in charge with the validation practice. The best way to put this in practice is to conduct a cession of trainings for all the stakeholders. Various training activities being held on a regular basis and making an essential part of the VALERU project, will ensure that the dissemination and implementation of the outcomes will start within the project's lifetime and continue beyond this. Expert teams will develop and run training courses for various target groups, thus multiplying the number of experts and contributing to better understanding of the validation ideas. The project materials envisioned not only in face-to-face, but also in e-format, making use of new technologies, including video-conferences. All the printed materials are presented on a special website of the VALERU project (http://valeru.net/en/russian-federation/). During the VALERU project were designed necessary key terms regarding the validation of non-formal and informal learning that hadn't existed in Russian Language. Thus, within the 
project's framework trainers will be trained, so that these can disseminate and, in this way, ensure the sustainability on the initiative of modernization of the HE systems. The next step of dissemination is to design small practically oriented programs in DSTU that combine experiential learning with the subject discipline based modules. Such programs mainly will include: individual (or part-individual and part-group) programs that are negotiated around a learning contract or agreement, recognition of previous learning, both for credit and as the starting-point for the programme and valid forms of assessment normally referenced to generic criteria representing the relevant academic level [24].

Then it is necessary to organize the promotional campaign to attract the students, create our own website with the relevant information. It is very important to monitor the development of validation procedures to exchange experiences, organize web-seminars.

Institutional support is vital for further success. It should be organized on both levels: administrative and methodological. Creation of a new syllabus, staff training, and organization of a study process demand united common efforts of the whole university team.

\section{Discussion}

Having a broad outlook on what have we done to move from the teacher-based to studentcentered education we should admit a great focus that is done on the enhancement of students' competitiveness on the labor market, their employability.

Our employers take part in the reviewing study programs and students' final assessment. Project work, scientific research, teamwork, business play; practical tasks are included into the technologies. Students have a free access to the study plan, syllabuses. All necessary information is on the website. Students have the right to choose subjects, themes of their practical work. To achieve this transformation we should firstly overcome the resistance to disseminate the new meta-language of education (VNIL) and innovative technologies. The key difficulty for Russia is the lack of relevant experience of such activities as formulating programs, counting credits, formulating comparable learning outcomes. Another major difficulty is that Russian universities have traditionally provided a broad academic education rather than specialized practice-oriented professional training. State Educational Standards elaborated in Russia do not allow sufficient freedom in designing educational programs. We only speak of the competence approach with a fixed number of competences (in some standards there are more than 80), formally observe Bologna principles of student-centered approach and often don/t observe the sequence and logics of the systematic model of validation. The new law introduced a concept of credit without direct relation to learning outcomes that does not correspond with the notion of ECTS. We have a lack of relevant methodology and it is difficult to validate a learning experience, as it is really a new model of learning.

Thinking over the value of VNIL process we believe that prospective students should be awarded academic credit for their prior learning as identified through the VNIL process. Academic credit should be awarded for past certificated learning - learning which has a recognized credit value. We also should award credit for current experiential learning, usually for workplace projects. You should reflect this fact in a designed Work Based Learning programs enabling students to negotiate a curriculum and award title relevant to their learning requirements in the workplace. The role of teachers will be different. In this case, they should be facilitators of the learning process. Students negotiate their own learning outcomes and how to demonstrate their achievement in the assessment process. They develop the cognitive ability through individual tuition and extensive use of formative assessment.

It is not an easy question to define the maximum credit for a university to award. The arrangements are different depending on the subject to be studied from two up to five credits. 


\section{Conclusion and recommendation}

The national system of education with its cultural, historical and mental peculiarities is unique and reflects the national specifics of the development of society and national pedagogical science. There is no strategy for non-formal education in Russia. What is clear is that, firstly, we need time to truly convert Russian HELs to the new system of non-formal and informal learning validation and, secondly, we should force HELs to apply the new format of validation starting with the change in mentality to lead to productive not mechanical application of the new language. The following challenges within the Russian context were spotted: current legislation in Russia, the Qualifications Framework, educational standards, the weakness of professional standards system, the issue of terminology, mismatch between curriculum and educational program, issue of credits vs. grading system, no standardized procedure in place, and lack of clarity for responsibility within the university, vagueness of experts competence. Russia is lacking of experience in VNIL validation, just participating in some international VALERU projects. It is very important to reflect, to debate, elaborate instruments, and share the results. The validation practice in Russia should meet the needs of people of different ages, especially adults, to implement the so-called lifelong learning in life. We should overcome our conservatism. The most evident contribution towards validation consist in bringing together competence-based education, student-centered and transparent learning outcomes comprehensible for all the stakeholders. Employers should be invited to plan the future professional development of students. Each participant country needs to develop procedures compatible with the existing national system. Moreover, we should admit that validation procedures in Europe and Russia differ due to different political, economic, legal circumstances. In Russia, validation is conducted mainly as academic validation as recognition of education abroad and secondly professional validation as allowance to work in Russian Federation. The realistic timetable for VNIL implementation in Russia depends on political will of our government, elaboration of legislation, launching student-centered, practice-oriented professional programs, and formulating measurable learning outcomes. We strongly believe that Russia has all necessary groundings for VNIL implementation and with the trainings of experts we will manage to overcome the obstacles to transformation.

\section{References}

1. S.L. Tudor, Procedia - Social and Behavioral Sciences 76, 821 - 826 (2013) doi: 10.1016/j.sbspro.2013.04.213

2. P. Coombs, M. Ahmed, Attacking Rural Poverty. How non-formal education can help (John Hopkins Press, Baltimore, 1974)

3. O. Moldovana, V. Bocoș-Bințințan, Procedia - Social and Behavioral Sciences 209, 337 - 343 (2015) doi: 10.1016/j.sbspro.2015.11.245

4. J. Abdullai, A. Tresi, K. Ramadani, Procedia - Social and Behavioral Sciences 46, 4923 - 4927 (2012) doi: 10.1016/j.sbspro.2012.06.360

5. D. Dewey, Psychology and pedagogy of thinking (Publishing House of Perfection, Moscow, 1997)

6. A. Demchuk, Y. Karavaeva, Y. Kovtun, S. Rodionova, Tuning Journal for Higher Education 1(3), 149-185 (2015) doi: 10.18543/tjhe-3(1)-2015pp149-185

7. D. Colardyn, J. Bjornavold, European Journal of Education 1(39), 69-89 (2004) doi: https://doi.org/10.1111/j.0141-8211.2004.00167.x 
8. A. Hassana, K. Osmanb, S. Pudin, Procedia Social and Behavioral Sciences 1, 23062311 (2009) doi:10.1016/j.sbspro.2009.01.405

9. P. Werguin, Recognizing Non-formal and Informal Learning: Outcomes, Policies and Practices (OECD Publishing, France, 2010) doi: 10.1787/9789264063853-en

10. L. Cooper, J. Harris, International Journal of Lifelong Education 4(32), 447-463 (2013) doi:10.1080/02601370.2013.778072

11. C. Sin, Studies in Higher Education 10(39), 1823-1837 (2014) doi: 10.1080/03075079.2013.806463

12. J. Kalendaa, Procedia - Social and Behavioral Sciences 174, 1077 - 1084 (2015) doi: 10.1016/j.sbspro.2015.01.797

13. J. Quinn, Policy Futures in Education 2(16), 144-155 (2017) doi: $10.1177 / 1478210317736223$

14. G. Tisza, S. Papavlasopoulou, D. Christidou, N. Iivari, M. Kinnula, I. Voulgari, International Journal of Child-Computer Interaction 25, 100184 (2020) https://doi.org/10.1016/j.ijcci.2020.100184

15. J. Talbot, Education and Science 1(4), 142-157 (2015) https://doi.org/10.17853/19945639-2015-4-142-157

16. M. Yudkevich, Studies in Higher Education 8(39), 1463-1474 (2014) doi: 10.1080/03075079.2014.949537

17. N. Gorshkov, G. Kliucharev, Russian Education and Society 8(55), 40-92 (2013) doi I: 10.2753/RES1060-9393550803

18. V. Mironov, Russian Education and Society 12(55), 3-63 (2013) doi: 10.2753/RES1060-9393551201

19. A. Ovsiannikov, Russian Education and Society 3(55), 34-67 (2013) doi: 10.2753/RES1060-9393550302

20. N. Sergeev, Education and Society 2(55), 82-97 (2013) doi: 10.2753/RES10609393550204

21. T.B. Mikheeva, E.V. Murugova, SHS Web Conf. 70, 07003 (2018) doi: https://doi.org/10.1051/shsconf/20197007003

22. E.V. Karavayeva, Y.N. Kovtun, Tuning Journal for Higher Education 1, 187-203 (2013) doi: http://dx.doi.org/10.18543/tjhe-1(1)-2013pp187-202

23. Terminology of European education and training policy (Publications office of the European Union Luxembourg, 2014) doi:10.2801/15877

24. L. Stan, C. Carol, Studies in Higher Education 35(5), 561-575 (2010) doi:10.1080/03075070903216635 